\title{
The association between CBS 844 ins68 polymorphism and head and neck squamous cell carcinoma risk - a case-control analysis
}

Ana L.S. Galbiatti ${ }^{1}$, Mariangela T. Ruiz¹, Luis S. Raposo², José V. Maniglia², Erika C. Pavarino-Bertelli', Eny M. Goloni-Bertollo ${ }^{1}$

\begin{abstract}
${ }^{1}$ Genetics and Molecular Biology Research Unit (UPGEM), Faculdade de Medicina de São José do Rio Preto (FAMERP) SP, Brazil

2Otorhinolaryngology and Head and Neck Surgery Department, Faculdade de Medicina de São José do Rio Preto (FAMERP) SP, Brazil
\end{abstract}

Submitted: 7 July 2010

Accepted: 17 August 2010

Arch Med Sci 2010; 6, 5: 772-779

DOI: 10.5114/aoms.2010.17094

Copyright (c) 2010 Termedia \& Banach

\section{Abstract}

Introduction: Susceptibility to head and neck squamous cell carcinoma may be modified by functional polymorphisms in genes involved in the folate pathway, such as cystathionine beta-synthase (CBS). The CBS 844ins68 polymorphism is associated with DNA methylation changes and cancer development.

Material and methods: A case-control retrospective study was conducted in 322 patients with head and neck squamous cell carcinoma and in 531 control subjects without cancer. The polymerase chain reaction-restriction fragment length polymorphism technique was used to genotype the polymorphism. For statistical analysis, $\chi^{2}$ test was conducted to examine whether the genotypic frequency of CBS 844ins68 was in Hardy-Weinberg equilibrium and multiple logistic regression was used for comparisons between groups, and for interactions between the polymorphism and risk factors and clinical histopathological parameters.

Results: No significant difference in CBS 844ins68 genotypic distribution was observed between the groups. Age > 50 years, male gender and tobacco consumption were predictors of the disease with increased risk of $7.89(95 \% \mathrm{Cl}$ : 5.56-11.21), 2.49 (95\% Cl: 1.72-3.62), 6.44 (95\% Cl: 4.63-8.96) and 2.29 times (95\% $\mathrm{Cl}: 1.71-3.06)$ respectively. There was no association between the distribution of the CBS 844ins68 genotype and risk factors for this disease. According to clinical histopathological parameters, CBS 884ins68 polymorphism presented high frequency in oral cavity $(p<0.05)$ and patients with the polymorphism presented less survival time $(p<0.05)$.

Conclusions: We concluded that the CBS 844ins68 polymorphism is not associated with HNSCC risk and there is increased risk of this disease in male gender individuals smokers aged over 50 years. In adittion, the polymorphism is more frequent in patients with oral cavity as primary site and in patients with less survival time.

Key words: genetic polymorphism, head and neck neoplasms, folate, metabolism, genes.

\section{Introduction}

Head and neck squamous cell carcinoma (HNSCC) is the fifth most common cancer worldwide and the most common neoplasm in the upper

\author{
Correspondence author: \\ Eny M. Goloni-Bertollo \\ Genetics and Molecular \\ Biology Research Unit \\ (UPGEM) \\ Faculdade de Medicina \\ de São José do Rio Preto \\ (FAMERP) SP \\ Av. Brigadeiro Faria Lima 5416 \\ 15090-000 Vila São José \\ São José do Rio Preto - SP, \\ Brazil \\ Phone: +55 1732015720 \\ E-mail: eny.goloni@famerp.br
}


aerodigestive tract. In Brazil, nearly 14,120 new cases of oral cancer are expected in 2010, comprising 3,790 in women and 10,330 in men [1]. Despite some advances in conventional therapies, including surgery, radiation and chemotherapy, the overall survival (OS) rate for HNSCC has not significantly improved in the last three decades [2].

The HNSCC anatomical region includes tumours of the oral cavity, pharynx and larynx and the most common histological type is squamous cell carcinoma, present in $95 \%$ of cases [2, 3]. Alcohol and tobacco use are common factors for HNSCC. Additionally, evidence is accumulating for a role of folate in cancer. Studies have shown a relationship between polymorphisms of genes involved in folate metabolism and the HNSCC risk because of their influence on methylation and synthesis of DNA [2, 4-11].

Methylation is responsible for gene expression control, chromatin structure stability and the maintenance of genomic stability. Folate, the methyl donor in reaction to cellular methylation, regulates the synthesis, methylation and repair of DNA when present in the body in adequate amounts. When folate is altered in consequence of polymorphism in this pathway, it disrupts the cell cycle and consequently may lead to cancer [5, 12-14].

The CBS gene encodes cystathionine beta synthase $(C B S)$, involved in the folate pathway, which is the central enzyme in the transsulfuration pathway that irreversibly metabolizes homocysteine (Hcy) (removes Hcy from the methionine) to cystathionine. It is polymorphic in nucleotide 844 - exon 8 (CBS 844ins68) with an insertion of 68 base pairs. Although the biological impact of this polymorphism remains unclear, it seems to be associated with reduction of Hcy levels and changes in DNA methylation because of the low availability of S-adenosylmethionine (SAdoMet), the main methyl donor for methylation reactions, and consequently DNA hypomethylation and carcinogenesis may occur [15-17].

The study of Le Marchand et al. [18] showed that the CBS 844ins68 variant allele may be protective against colorectal cancer, but this association occurs together with other polymorphisms of the folate pathway. The study of Pufulete et al. [19] did not find an association with colorectal cancer. Other studies also did not confirm an association between the polymorphism and carcinomas of the upper gastrointestinal tract [20] and prostate cancer [21].

The association between head and neck squamous cell carcinoma and CBS 844ins68 polymorphism has not been tested until now; thus, we have conducted this case-control study in 853 individuals to investigate the association between CBS 844ins68 polymorphism and HNSCC aetiology. Therefore, this study aimed to investigate the frequency of CBS 844ins68 in head and neck squamous cell carcinoma patients, to compare the results with individuals without cancer, and to evaluate the association of the polymorphism with risk factors (tobacco and alcohol habits) and clinical histopathological parameters.

\section{Material and methods}

\section{Study subjects}

At first, the study protocol was approved by the National Ethics Committee (CONEP - 5566/2005; SISNEP 0976.0.140.000-05).

The retrospective study population included a total of eight hundred and fifty-three subjects (322 patients and 531 controls) with a mean age of $52.5 \pm 13.7$ years. The case group ( $86.7 \%$ men and $13.3 \%$ women) was treated at the Hospital de Base, a Public Institution, São José do Rio Preto, São Paulo, Brazil. Diagnosis was made from pathological specimens after either total excision or biopsy. Patients with squamous cell carcinoma tumour cell types were included and patients previously treated for tumours were excluded.

The tumours were classified according to the TNM classification following three criteria: extension of the tumour $(\mathrm{T})$, presence of regional lymph node involvement $(\mathrm{N})$ and presence of metastasis at a distance (M) [22]. The clinical stage (TNM) was used to analyse aggressiveness, with tumours being grouped as non-aggressive (stage I and II) and aggressive (stage III and IV). All required information about clinical histopathological parameters was obtained from the patients' medical records.

The control group comprised Brazilian blood donors (72.3\% men and $27.7 \%$ women) without cancer according to the government guidelines for blood donation which include tests for 20 related diseases (http://www.hemonline.com.br/portarias/ rdc153/indexframe.htm). Individuals with family history of cancer were excluded and individuals aged over 40 years were included in this study. Each eligible subject was interviewed to obtain data on age, gender, smoking habits, use of alcohol and familial history of cancer.

The variables analysed were gender, exposure to risk factors (tobacco and alcohol consumption), and primary site of occurrence, aggressiveness, extension of the tumour and lymph node involvement. Individuals who had smoked more than 100 cigarettes during their lifetime were considered smokers. Individuals who drank four units of alcohol per week were considered alcohol consumers [23, 24].

\section{Genotyping of CBS 844ins68}

To determine the individual genotypes, genomic DNA was obtained from peripheral blood according to the technique of Miller et al. [25]. Molecular 
analysis of the CBS 844ins68 polymorphism was performed according to PCR technique (polymerase chain reaction) observing the difference in size of amplification products, using primer sequences described by Dutta et al. [26].

Amplification was obtained with initial denaturation at $94^{\circ} \mathrm{C}$ for $4 \mathrm{~min}$, followed by 30 cycles of 1 minute of DNA denaturation at $94^{\circ} \mathrm{C}$, $1 \mathrm{~min}$ of primer annealing at $62^{\circ} \mathrm{C}$ and $1 \mathrm{~min}$ of extension at $72^{\circ} \mathrm{C}$. A final extension of $5 \mathrm{~min}$ at $72^{\circ} \mathrm{C}$ was carried out. The PCR products were run onto $1.5 \%$ agarose gel, stained with ethidium bromide and visualized in UV illumination. The CBS gene thus included (I) or lacked (N) a 68 base pairs (bp) insertion at exon 8 . The major allele (I) presented a $239 \mathrm{bp}$ fragment and the normal allele presented a 171 bp fragment. Fragment sizes were estimated by comparing with a 100 bp DNA size marker.

\section{Statistical analysis}

Statistical analysis was performed using Minitab software (Windows, Version 14.0) and the BioEstat program. Chi-square tests were conducted to examine whether the genotype frequency of $C B S$ 844ins68 was in Hardy-Weinberg equilibrium (HWE).

Differences in gender (reference: female), tobacco (reference: non-smokers) and alcohol habits (reference: non-drinkers) between the cases and controls were evaluated using multiple logistic regression analysis. This model was also used to determine the interaction effect between the genetic polymorphism and variables related to head and neck squamous cell carcinoma.

The clinical histopathological parameters were analysed by multiple logistic regression. Tumours were classified as low $\mathrm{T}(\mathrm{T} 1, \mathrm{~T} 2)$ and high $\mathrm{T}(\mathrm{T} 3$, $\mathrm{T} 4)$. The $\mathrm{N}$ classification was dichotomized into no lymph node involvement (NO) and involvement (N1, N2, N3). Tumours were divided into early stage (stages I and II) and advanced stage (stages III and IV) categories. A $p$ value $<0.05$ was considered statistically significant. Results are shown as odds ratio (OR) and $95 \%$ confidence intervals $(95 \% \mathrm{Cl})$.

The Kaplan-Meier method was used to evaluate survival rates and recurrence time of disease. The log-rank test was used to assess differences related to the different genotypes.

\section{Results}

\section{Demographic data and lifestyle factors}

The case group with a mean age of 58.4 (9.9) years presented a predominance of tobacco $(80.7 \%)$ and alcohol consumers (69.2\%). The mean age of the control group was 47.4 (13.1) years, $40.4 \%$ tobacco users and $49.2 \%$ alcohol consumers.

As matching demographic data and risk factors between patients with cancer and control individuals was not possible, multivariable analysis was performed to adjust these variables. There were statistically significant differences between patients and controls according to age $>50$ years (OR 7.89, 95\% Cl: 5.56-11.21, $p<0.05$ ), male gender (OR 1.05, 95\% Cl: 1.05-2.67, $p<0.05$ ) and tobacco users (OR 4.09, 95\% Cl, 2.77-6.03, $p<0.05$ ).

\section{CBS genotype}

The Hardy-Weinberg equilibrium showed that the genotypic distributions were not expected in both groups and they were not in equilibrium (case: $\chi^{2}=4.98, p=0.02$ and control: $\chi^{2}=8.05, p=0.004$ ).

The genotypic and allelic distributions of the CBS 844ins68 polymorphism were compared between the groups and did not show statistically significant differences. Of 854 individuals studied, 702 (82.2\%, 443 controls and 259 patients) comprising did not have the polymorphism; 18 (2.1\%, 10 controls and 8 patients) presented CBS 844ins68 polymorphism, and 134 (15.7\%, 78 controls and 56 patients) had the heterozygous genotype for the polymorphism (Table I).

The potential interaction between the distribution of the CBS 844ins68 genotype and exposure to risk factors for head and neck

Table I. Distribution of the CBS 844ins68 polymorphism between HNSCC patients and controls

\begin{tabular}{|c|c|c|c|c|}
\hline CBS 844ins68 polymorphism & Patients, $n(\%)$ & Controls, $n(\%)$ & OR $(95 \% \mathrm{Cl})$ & $p$ \\
\hline Genotypes & $n=322$ & $n=531$ & & \\
\hline NN (Non-insertion) & $258(80)$ & $443(83.4)$ & 1.00 (ref) & \\
\hline IN (Heterozygous) & $56(17.5)$ & $78(14.6)$ & $1.15(0.74-1.79)$ & 0.53 \\
\hline II (Polymorphic) & $08(2.5)$ & $10(2.0)$ & & \\
\hline \multicolumn{5}{|l|}{ Alleles } \\
\hline Non-insertion (N) 68 bp & $315(83.1)$ & $521(82.8)$ & 1.00 (ref) & \\
\hline Insertion 68 bp(I) & $64(16.9)$ & $88(17.2)$ & $1.20(0.85-1.71)$ & 0.30 \\
\hline
\end{tabular}

NN - 68 bp non-insertion, IN - heterozygous - CBS 844ins68, II - CBS 844ins68 polymorphic. Adjusted for age, gender, tobacco and alcohol habits. The genotypes was calculated for polymorphic homozygous individuals or carrying risk allele heterozygous vs. wild-type homozygous. $p<0.05$ was considered significant. There was no difference statistically significant (multiple logistic regression) 
The association between CBS 844ins68 polymorphism and head and neck squamous cell carcinoma risk - a case-control analysis

Table II. Odds Ratio of head and neck cancer related to CBS genotypes by age, gender, tobacco and alcohol habits

\begin{tabular}{|c|c|c|c|c|c|}
\hline Variables & $\begin{array}{l}\text { NN genotype } \\
\text { (case/controls) }\end{array}$ & OR $(95 \% \mathrm{Cl})$ & $\begin{array}{l}\text { IN and II genotypes } \\
\text { (cases/controls) }\end{array}$ & OR $(95 \% \mathrm{Cl})^{*}$ & $p$ \\
\hline \multicolumn{6}{|l|}{ Age } \\
\hline$<50$ & $53 / 313$ & 1.00 (ref) & $10 / 60$ & $1.19(0.55-2.57)$ & 0.66 \\
\hline$>50$ & $205 / 130$ & 1.00 (ref) & $54 / 28$ & $1.18(0.68-2.03)$ & 0.55 \\
\hline \multicolumn{6}{|l|}{ Gender } \\
\hline Female & $34 / 125$ & 1.00 (ref) & $08 / 22$ & $1.34(0.49-3.65)$ & 0.56 \\
\hline Male & $224 / 318$ & 1.00 (ref) & $56 / 66$ & $1.12(0.68-1.83)$ & 0.65 \\
\hline \multicolumn{6}{|c|}{ Tobacco habits } \\
\hline No & $47 / 261$ & 1.00 (ref) & $12 / 55$ & $1.14(0.52-2.50$ & 0.73 \\
\hline Yes & $211 / 182$ & 1.00 (ref) & $52 / 33$ & $1.14(0.66-1.95$ & 0.64 \\
\hline \multicolumn{6}{|c|}{ Alcohol habits } \\
\hline No & $81 / 221$ & 1.00 (ref) & $18 / 48$ & $1.10(0.55-2.19)$ & 0.78 \\
\hline Yes & $177 / 222$ & & $46 / 40$ & $1.21(0.67-2.17)$ & 0.53 \\
\hline \multicolumn{6}{|c|}{ Tobacco and alcohol habits } \\
\hline No & $38 / 151$ & 1.00 (ref) & $08 / 36$ & $0.79(0.31-1.98)$ & 0.61 \\
\hline Yes & $168 / 112$ & & $42 / 21$ & $1.04(0.56-1.93)$ & 0.90 \\
\hline
\end{tabular}

CBS cystathionine $\beta$-synthase: NN - 68 bp non-insertion, IN - heterozygous - CBS 844ins68, II - CBS 844ins68 polymorphic genotype ${ }^{*}$ Ajusted for age, gender, tobacco and alcohol habits. CBS IN and II genotype compared with variables - reference: CBS NN; $p<0.05$ was considered significant. None of the differences between groups were statistically significant by multiple logistic regression

squamous cell carcinoma are shown in Table II, with no statistical difference.

\section{Clinical histopathological parameters and CBS} polymorphism

Only patients with complete pathological data were considered for this analysis. There were significant associations of individuals with IN and Il genotypes (at least one 68p insertion allele) with oral cavity (OR 1.93, 95\% Cl: 1.10-3.40, $p<0.05$ ) (Table III). The analysis of metastasis classification was not performed since all patients were classified as MO.

The Kaplan-Meier survival curves by genotype are presented in Figure 1. There was an association between polymorphism and survival time $(p=0.02)$ (Figure 1A), and no association between polymorphism and recurrence time of the disease (Figure 1B, $p=0.52$ ).

Table III. Distribution of the clinical histopathological parameters and CBS polymorphism*

\begin{tabular}{|c|c|c|c|c|c|}
\hline Variables & NN genotype & OR $(95 \% \mathrm{Cl})$ & IN/II genotype & OR $(95 \% \mathrm{Cl})^{\star \star}$ & $p$ \\
\hline \multicolumn{6}{|l|}{ Site of tumor } \\
\hline Oral cavity & 97 & 1.00 (ref) & 33 & $1.93(1.10-3.40)$ & $<0.05$ \\
\hline Pharynx & 65 & 1.00 (ref) & 15 & $0.92(0.48-1.76)$ & 0.92 \\
\hline Larynx & 85 & 1.00 (ref) & 12 & $0.83(0.50-1.36)$ & 0.45 \\
\hline Unknown primary site & 11 & 1.00 (ref) & 05 & $1.50(0.46-4.88)$ & 0.50 \\
\hline \multicolumn{6}{|l|}{ Tumor extension } \\
\hline $\mathrm{T} 1 / \mathrm{T} 2$ & 106 & 1.00 (ref) & 28 & 1.00 (ref) & \\
\hline $\mathrm{T} 3 / \mathrm{T} 4$ & 118 & 1.00 (ref) & 29 & $0.48(0.27-0.86)$ & 0.63 \\
\hline \multicolumn{6}{|l|}{$\mathrm{N}$ involvement } \\
\hline No & 11 & 1.00 (ref) & 01 & 1.00 (ref) & \\
\hline Yes & 213 & 1.00 (ref) & 56 & $1.47(0.37-5.75)$ & 0.58 \\
\hline
\end{tabular}

CBS cystathionine $\beta$-synthase: NN - 68 bp non-insertion, IN-heterozygous - CBS 844ins68, II - CBS 844ins68 polymorphic genotype ${ }^{*}$ The analysis was made to patients with complete data. CBS IN and II genotype compared with clinical histopathological parameters - reference: CBS NN; $p<0.05$ was considered significant. There was difference statistically significant between oral cavity and CBS polymorphism (multiple logistic regression) 
A

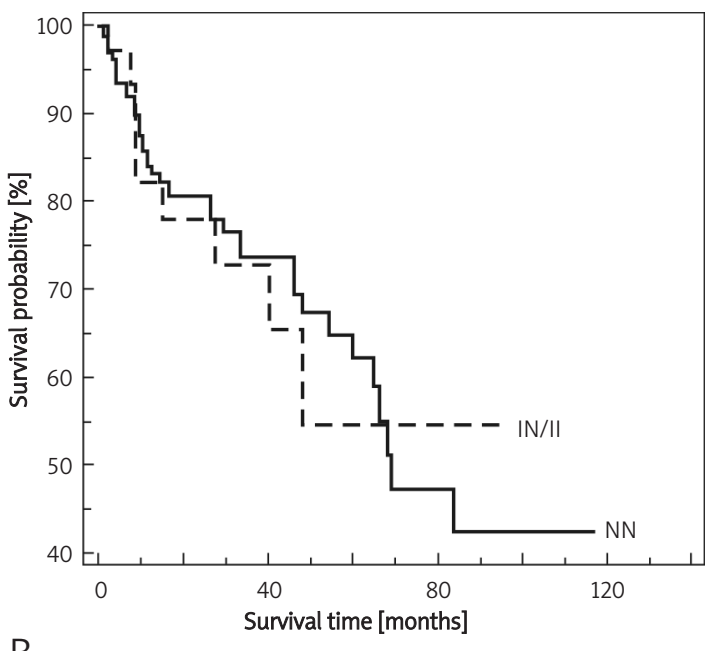

B

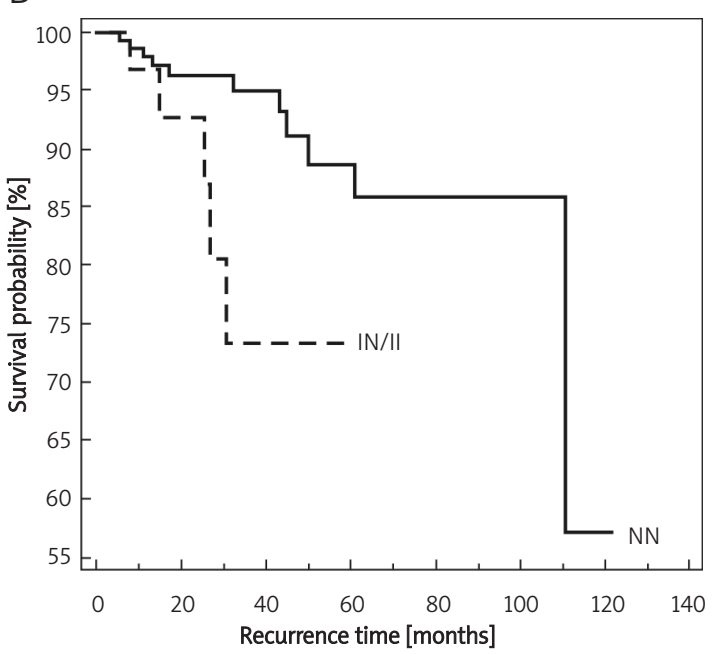

Figure 1. Kaplan-Meier curves for the survival time $(p=0.02)(\mathrm{A})$ and recurrence time $(p=0.89)(\mathrm{B})$ for patients according to the CBS 844ins68 polymorphism. There was statistical difference between the curve for subjects with at least one polymorphic allele (I or IN genotype) with survival time $N N$ - non-insertion, II-polymorphic, IN - heterozygous

\section{Discussion}

The results showed that HNSCC is more common in male smokers aged over 50 years. Previous studies have shown that male gender, alcohol and tobacco consumption are the most important predisposing factors for this disease [2, 27-29]. In our study, however, alcohol consumption was not associated with HNSCC. A multicentre study confirmed that tobacco is a strong risk factor for HNSCC independent of alcohol consumption [30]. Moreover, studies in animal models showed that alcohol did not have a direct carcinogenic effect and it is not genotoxic. This agent suppresses the removal of nitrosamine molecules of low molecular weight released by the tobacco in the liver through inhibition of multiple isoforms of the cytochrome P450 superfamily. Thus, there is an increase of nitrosamines to the posthepatic tissues and an increase in the formation of DNA adducts [31-33].

Male gender remains the most affected by this tumour type as shown in our findings. However, the female gender has been presenting higher proportions [27, 29], due to the habits of the smoking and alcohol consumption have increased among women [2].

According to Hardy-Weinberg equilibrium (HWE) analysis, our study showed that the CBS gene is not in HWE. The departure from the HWE may result from the random selection of the studied individuals, the disease model adopted, and evolutionary factors which can influence changes in the genotype frequencies [34, 35]. On the other hand, this disequilibrium should be expected, considering that it reflects biological and genetic characteristics in complex disease models [36].

In our case-control study the CBS 68 bp insertion allele (I) was not statistically significantly associated with HNSCC risk (OR 1.20, 95\% Cl: 0.85-1.71, $p=0.30)$; nor with heterozygous genotype $(\mathrm{I} / \mathrm{N})$ or polymorphic homozygous genotype (I/I), with OR of 1.15 (95\% Cl: $0.74-1.79, p=53)$. We did not find evidence that the CBS 844ins68 polymorphism may contribute to the individual risk for the development of head and neck squamous cell carcinoma, in as studies of Kimura et al. [21] and Ott et al. [20] in prostate and upper gastrointestinal tract cancer, respectively.

Ott et al. [20] investigated the insertion of $68 \mathrm{bp}$ in the CBS gene with susceptibility to carcinomas of the upper gastrointestinal tract. They studied 263 patients with oesophageal cancer, 89 patients with Barrett's oesophagus-associated oesophageal adenocarcinoma, 144 with cardiac carcinoma, 221 with gastric cancer and 257 healthy subjects, and they did not find an association with these neoplasms. The study of Kimura et al. [21] in 132 patients with prostate cancer and 150 individuals without cancer, and the study of Pufullete et al. [19] that investigated 35 patients with adenoma, 28 patients with colorectal cancer and 76 controls did not found association with cancer risk.

The study of Le Marchand et al. [18] found an association of CBS 844ins68 and cancer risk. They investigated 727 Japanese, Caucasian, or Native Hawaiian colorectal cases and 727 controls without neoplasia matched for sex, age, and ethnicity and showed that CBS 844ins68 variant allele may be weakly protective against colorectal cancer, but this effect occurs only if this variant acts together with the T allele (variant) of MTHFR C677T polymorphism.

Our results for a potential interaction between the distribution of the CBS 844ins68 genotype and exposure to risk factors for head and neck squamous cell carcinoma did not show any 
statistically significant association. Kimura et al. [21] found that the insertion allele was slightly more prevalent among females in homozygous or heterozygous form in the control group, and the polymorphic allele was rarer in older patients, but these differences were not statistically significant.

This polymorphism resides in a key enzyme of the one-carbon metabolism pathway and it may result in aberrant DNA synthesis which may result in uncontrolled growth, but no study presented significant results for CBS 844ins68 polymorphism and cancer risk [15-17]. To our knowledge, this is the first study of CBS 844ins68 and HNSCC risk and despite the few studies in cancer, some studies have found an association of this polymorphism with other diseases, such as schizophrenia [37], neural tube defects [38], Alzheimer's disease [39] and coronary artery disease [40].

The CBS 844ins68 polymorphism was first reported in a homocystinuric patient by Sebastio et al. [41]. It was initially thought to mandate the use of an insertion-associated premature stop codon in the CBS mRNA leading to the translation of a truncated inactive enzyme. Subsequently Tsai et al. [15] showed that the $68 \mathrm{bp}$ insertion generates an alternative splice site that permits the elimination of the entire inserted region, thereby allowing the formation of a normal mRNA transcript and a fully functional CBS enzyme. In 1998, De Stefano et al. [42] reported that MTHFR 677TT homozygous individuals carrying the CBS 844ins68 allele had lower homocysteine levels than non-carriers; however, folate levels were not presented in this report. More recently, Dekou et al. [43] also reported that the CBS 844ins68 allele appears to have a homocysteine-lowering effect in MTHFR 677TT homozygous individuals, but again no data were reported regarding the effect on folate levels.

In our study, it was not possible to measure the homocysteine and folate concentrations, but studies have reported that individuals who have the 68 bp insertion had increased homocysteine and folate levels compared with wild-type individuals [44, 45].

For clinical histopathological parameters analysed, our results suggest that the CBS Insertion $68 \mathrm{bp}$ allele was more frequent in patients with the oral cavity as the primary site. The tumour extent and lymph node involvement were not associated with the presence of the polymorphism. Kimura et al. [21] did not observe any association between the polymorphism and clinical parameters in prostate cancer.

The majority of HNSCC patients showed less advanced stage classified as T1/T2 and NO (54.3\% and $96 \%$, respectively) in our study. Different of the literature data, which have shown a high frequency of head and neck squamous cell carcinoma in advanced stage (60\% in stage III and IV) [46]. However, in gastric and cardiac cancer category tumour size T1 and T2 was more prevalent, as in our study in HNSCC [20].

No data were found in the literature assessing survival according to the CBS 844ins68 polymorphism in patients with HNSCC. According to Esher et al. [47], patients with HNSCC have a low survival rate among some cancer types. In spite of new surgical techniques, such as radiotherapy and concomitant chemotherapy, there has not been a significant increase in survival rate [48-50].

In conclusions, male gender and tobacco consumption are associated with HNSCC risk and there is no evidence of an association between CBS polymorphism and head and neck carcinogenesis risk. The polymorphism was associated with oral cavity primary site and with less survival time. Further studies in a larger population are required to better understand this polymorphism.

\section{Acknowledgments}

The authors wish to thank all those participating in this study, Prof. Adília M. Pires Sciarra for her help in writing the text, Fundação de Amparo à Pesquisa do Estado de São Paulo (FAPESP), Coordenação de Pessoal de Nível Superior (CAPES), Centro Nacional de Desenvolvimento Científico e Tecnológico (CNPq) and FAMERP/FUNFARME.

\section{References}

1. Estimativas de câncer oral para 2010 no Brasil, INCA 2010. http:www.inca.gov.br/estimativa/2010/index.asp. Acessed in 2010 (May, 20).

2. Marcu LG, Yeoh E. A review of risk factors and genetic alterations in head and neck carcinogenesis and implications for current and future approaches to treatment. J Cancer Res Clin Oncol 2009; 135: 1303-14.

3. Salzwimmer M. Best supportive care in HNSCC. Wien Med Wochenschr 2008; 158: 278-82.

4. Zhang Z, Shi Q, Liu Z, Sturgis EM, Spitz MR, Wei Q. Polymorphisms of Methionine Synthase and Methionine Synthase Reductase and Risk of Squamous Cell Carcinoma of the Head and Neck: a Case-Control Analysis. Cancer Epidemiol Biomark Prev 2005; 14: 1188-93.

5. Kane MA. The role of folates in squamous cell carcinoma of the head and neck. Canc Detect and Prev 2006; 29: 46-53.

6. Xu WH, Shrubsole MJ, Xiang YB, et al. Dietary folate intake, MTHFR genetic polymorphisms, and the risk of endometrial cancer among Chinese women. Cancer Epidemiol Biomarkers Prev 2007; 16: 281-7.

7. Solomon PR, Selvam GS, Shanmugam G. Polymorphism in $\mathrm{ADH}$ and MTHFR genes in oral squamous cell carcinoma of Indians. Oral Diseas 2008; 14: 633-9.

8. Smith AD, Kim YI, Refsum H. Is folic acid good for everyone? Am J Clin Nutr 2008; 87: 517-33.

9. Li D, Diao Y, Li H, Fang X, Li H. Association of the polymorphisms of MTHFR C677T, VDR C352T, and MPO G463A with risk for esophageal squamous cell dysplasia and carcinoma. Arch Med Res 2008; 39: 594-600. 
10. Jin F, Qu LS, Shen XZ. Association between the methylenetetrahydrofolate reductase C677T polymorphism and hepatocellular carcinoma risk: a metaanalysis. Diag Patholog 2009; 4: 39.

11. Kruszyna L, Lianeri M, Rydzanicz M, Gajecka M, Szyfter K, Jagodzinski PP. Polymorphic variants of folate metabolism genes and the risk of laryngeal cancer. Mol Biol Rep 2009; 37: 241-7.

12. Ehrlich M. Expression of various genes is controlled by DNA methylation during mammalian development. J Cell Biochem 2003; 88: 899-910.

13. Sciandrello G, Caradonna F, Mauro M, Barbata G. Arsenicinduced DNA hypomethylation affects chromosomal instability in mammalian cells. Carcinogenesis 2004; 25: 413-7

14. D'Alessio AC, Szyf M. Epigenetic tête-à-tête: the bilateral relationship between chromatin modifications and DNA methylation. Biochem Cell Biol 2006; 84: 463-76.

15. Tsai MY, Bignell M, Schwichtenberg K, Hanson NQ. High prevalence of a mutation in the cystathionine-b-synthase gene. Am J Hum Genet 1996; 59: 1262-7.

16. Tsai MY, Bignell M, Yang F, Welge BG, Graham KJ, Hanson NQ. Polygenic influence on plasma homocysteine: association of two revalent mutations, the 844ins 68 of cystathionine b-synthase and A2756G of methionine synthase, with lowered plasma homocysteine levels. Atherosclerosis 2000; 149: 131-7.

17. Bailey LB. Folate, methyl-related nutrients, alcohol, and the MTHFR 677C-->T polymorphism affect cancer risk: intake recommendations. J Nutr 2003; 133 (Suppl. 1): 3748-53.

18. Le Marchand L, Donlon T, Hankin JH, Kolonel LN, Wilkens LR, Seifried A. B-vitamin intake, metabolic genes, and colorectal cancer risk (United States). Cancer Causes Control 2002; 13: 239-48.

19. Pufulete M, Al-Ghnaniem R, Leather AJM, et al. Folate status, genomic DNA hypomethylation, and risk of colorectal adenoma and cancer: a case control study. Gastroenterology 2003; 124: 1240-8.

20. Ott N, Geddert H, Sarbia M. Polymorphisms in methionine synthase (A2756G) and cystathionine beta-synthase (844ins68) and susceptibility to carcinomas of the upper gastrointestinal tract. J Cancer Res Clin Oncol 2008; 134: 405-10.

21. Kimura F, Franke KH, Steinhoff C, et al. Methyl group metabolism gene polymorphisms and susceptibility to prostatic carcinoma. Prostate 2000; 45: 225-31.

22. Sobin $\mathrm{LH}$, Wittelind $\mathrm{CH}$. Internacional union against cancer: TNM classification of malignant tumours. $6^{\text {th }}$ edition. Wiley, New York 2000.

23. Ahrendt SA, Chown JT, Yang SC, et al. Alcohol comsuption and cigarette smoking increase the frequency of p53 mutations in nomsmall cell lung cancer. Cancer Res 2000 60: 3155-9.

24. Kjaerhein K, Gaard M, Andersen A. The role of alcohol, tobacco, and dietary factors in upper aerogastric tract cancer: a prospective study of 10.900 Norwegian men. Cancer Causes Control 1998; 9: 99-108.

25. Miller SA, Dikes DD, Polesky HF. A simple salting out procedure for extracting DNA from human nucleated cells. Nucleic Acids Res 1988; 16: 1215.

26. Dutta S, Sinha S, Chattopadhyay A, et al. Cystathionine beta-synthase T833C/844INS68 polymorphism: a familybased study on mentally retarded children. Behav Brain Func 2005; 26: 1-25.

27. Argiris A, Karamouzis MV, David Raben D, Ferris RL. Head and neck cancer. J Lancet 2008; 371: 1695-709.

28. Hashibe M, Brennan P, Benhamou S, et al. Alcohol drinking in never users of tobacco, cigarette smoking in never drinkers, and the risk of HNSCC: pooled analysis in the International HNSCC Epidemiology Consortium. J Natl Cancer Inst 2007; 99: 777-89.

29. Lung T, Tăşcău OC, Almăşan HA, Mureşan O. Head and neck cancer, epidemiology and histological aspects Part 1: a decade's results 1993-2002. J Craniomaxillofac Surg 2007; 35: 120-5.

30. Ragin CCR, Modugno F, Gollin SM. The epidemiology and risk factors of head and neck cancer: a focus on human papillomavirus. J Dent Res 2007; 86: 104-14.

31. Hashibe M, Brennan P, Benhamou S, et al. Alcohol drinking in never users of tobacco, cigarette smoking in never drinkers, and the risk of head and neck cancer: pooled analysis in the International Head and Neck Cancer Epidemiology Consortium. J Natl Cancer Inst 2007; 99: 777-89. Erratum in: J Natl Cancer Inst. 2008; 100: 225.

32. Boffeta P, Hashibe M. Alcohol and cancer. Lancet Oncol 2006; 7: 149-56.

33. Warnakulasuriya S, Sutherland G, Scully C. Tobacco, oral cancer, and treatment of dependence. Oral Oncol 2008; 41: 244-60.

34. Xu J, Turner A, Little J, Bleecker ER, Meyers DA. Positive results in association studies are associated with departure from Hardy-Weinberg equilibrium: hint for genotyping error? Hum Genet 2002; 111: 573-4.

35. Llorca J, Prieto-Salceda D, Combarros O, Dierssen-Sotos T, Berciano J. Competing risks of death and Hardy-Weinberg equilibrium in case-control studies of gene-disease association. Gac Sanit 2005; 19: 321-4.

36. Wittke-Thompson JK, Pluzhnikov A, Cox NJ. Rational inferences about departures from Hardy-Weinberg equilibrium. Am J Hum Genet 2005; 76: 967-86.

37. Golimbet V, Korovaitseva G, Abramova L, Kaleda V. The 844 ins68 polymorphism of the cystathionine betasynthase gene is associated with schizophrenia. Psychiatry Research 2009; 170: 168-71.

38. Martinez CA, Northrup H, Lin Jl, et al. Genetic association study of putative functional single nucleotide polymorphisms of genes in folate metabolism and spina bifida. Am J Obstet Gynecol 2009; 201: 394e1-11.

39. Beyer K, Lao J, Carrato C, et al. Cystathionine beta synthase as a risk factor for Alzheimer disease. Curr Alzheimer Res 2004; 1: 127-33.

40. Janosíková B, Pavlíková M, Kocmanová D, et al. Genetic variants of homocysteine metabolizing enzymes and the risk of coronary artery disease. Mol Genet Metab 2003; 79: 167-75.

41. Sebastio G, Sperandeo MP, Panico M, de Franchis R, Kraus JP, Andria G. The molecular basis of homocystinuria due to cystathionine beta-synthase deficiency in Italian families, and report of four novel mutations. Am J Hum Genet 1995; 56: 1324-33.

42. De Stefano V, Dekou V, Nicaud V, et al. Linkage disequilibrium at the cystathionine beta synthase (CBS) locus and the association between genetic variation at the CBS locus and plasma levels of homocysteine. The Ears II Group. European Atherosclerosis. Research Study. Ann Hum Genet 1998; 62: 481-90.

43. Dekou V, Gudnason V, Hawe E, Miller GJ, Stansbie D, Humphries SE. Gene-environment and gene-gene interaction in the determination of plasma homocysteine levels in healthy middle-aged men. Thromb Haemost 2001; 85: 67-74.

44. Fredriksen A, Meyer K, Ueland PM, Vollset SE, Grotmol T, Schneede J. Large-scale population-based metabolic phenotyping of thirteen genetic polymorphisms related to one-carbon metabolism. Hum Mutat 2007: 28: 856-65. 
45. Summers C, Hammons AL, Mitchell LE, Woodside JV. Influence of the cystathionine beta-synthase 844ins68 and methylenetetrahydrofolate reductase $677 \mathrm{C}>\mathrm{T}$ polymorphisms on folate and homocysteine concentrations. Eur J Hum Genet 2008; 16: 1010-3.

46. Herchenhorn D, Dias FL. Advances in radiochemotherapy in the treatment of head and neck cancer. Rev Hosp Clin 2004; 59: 39-46.

47. Escher A, Piotet E, Waridel F, Iggo R, Monnier P. p53 mutation in histologically normal mucosa of the aerodigestive tract is not a marker of increased risk for second primary carcinoma in head and neck cancer patients. Eur Arch Otorhinolaryngol 2009; 266: 547-51.

48. Tachezy R, Klozar J, Rubenstein L, et al. Demographic and risk factors in patients with head and neck tumors. J Med Virol 2009; 81: 878-87.

49. Mitani T, Hoshikawa H, Mori T, et al. Growth inhibition of head and neck carcinomas by d-allose. Head Neck 2009; 31: 1049-55.

50. Farshadpour F, Hordijk GJ, Koole R, Slootweg PJ. Head and neck squamous cell carcinoma in non-smoking and nondrinking patients with multiple tumors: etiologic significance of p53 and Ki-67 in non-tumorous epithelium. J Oral Pathol Med 2008; 37: 549-54. 